\title{
BMJ
}

\section{Body mass index cut offs to define thinness in children and adolescents: international survey}

\author{
Tim J Cole, professor of medical statistics, ${ }^{1}$ Katherine M Flegal, senior research scientist,, ${ }^{2}$ Dasha \\ Nicholls, consultant child and adolescent psychiatrist, ${ }^{3}$ Alan A Jackson, professor of human nutrition ${ }^{4}$
}

${ }^{1}$ Centre for Paediatric Epidemiology and Biostatistics, UCL Institute of Child Health, London WC1N 1EH

${ }^{2}$ National Center for Health

Statistics, Centers for Disease

Control and Prevention,

Hyattsville MD 20782, USA

${ }^{3}$ Department of Child and

Adolescent Mental Health, Great

Ormond Street Hospital for

Children, London

${ }^{4}$ Institute of Human Nutrition,

University of Southampton,

Southampton

Correspondence to: TJ Cole tim.

cole@ich.ucl.ac.uk

doi:10.1136/bmi.39238.399444.55

\section{ABSTRACT}

Objective To determine cut offs to define thinness in children and adolescents, based on body mass index at age 18 years.

Design International survey of six large nationally representative cross sectional studies on growth.

Setting Brazil, Great Britain, Hong Kong, the Netherlands, Singapore, and the United States.

Subjects 97876 males and 94851 females from birth to 25 years.

Main outcome measure Body mass index (BMI, weight/ height $^{2}$ ).

Results The World Health Organization defines grade 2 thinness in adults as BMI $<17$. This same cut off, applied to the six datasets at age 18 years, gave mean BMI close to a $z$ score of -2 and $80 \%$ of the median. Thus it matches existing criteria for wasting in children based on weight for height. For each dataset, centile curves were drawn to pass through the cut off of BMI 17 at 18 years. The resulting curves were averaged to provide age and sex specific cut-off points from 2-18 years. Similar cut offs were derived based on BMI 16 and 18.5 at 18 years, together providing definitions of thinness grades 1,2 , and 3 in children and adolescents consistent with the WHO adult definitions.

Conclusions The proposed cut-off points should help to provide internationally comparable prevalence rates of thinness in children and adolescents.

\section{INTRODUCTION}

Much has been written about the epidemic of child obesity ${ }^{1}$ but malnutrition - meaning undernutritionin infants, children, and adolescents poses a considerably larger public health problem internationally, ${ }^{2-5}$ and in the developed world anorexia nervosa is the third most common chronic condition of adolescence. $^{6}$ Obesity and malnutrition represent opposite extremes on the spectrum of adiposity, and both are routinely quantified in terms of weight and height relative to the child's age. ${ }^{7}$ Yet the classification of malnutrition in later childhood and adolescence is currently unsatisfactory because of the lack of suitable cut offs for international use. ${ }^{8}$

Fifty years ago Gomez introduced his malnutrition classification of weight below a specified percentage of median weight for the child's age. ${ }^{9}$ This included three components: a measurement, a reference for age adjustment, and a set of cut offs. ${ }^{10}$ Later Seoane and Latham proposed splitting weight for age into weight for height and height for age, ${ }^{11}$ allowing underweight to be defined as wasting or stunting, or both. ${ }^{12}$ Subsequently Waterlow et al recommended the use of $\mathrm{z}$ scores for the definitions of underweight, wasting, and stunting, with the cut offs defined in terms of standard deviations (SDs) below the median rather than as percentages of the median. ${ }^{13}$ This ensures that the false positive screening rate is constant across age as applied to the reference population. ${ }^{10}$

In 1983 the World Health Organization (WHO) formally recognised the US National Center for Health Statistics (NCHS) classification ${ }^{14}$ as the international reference ${ }^{15}$ and has used it since to classify children as underweight, wasted, or stunted, each based on a cut off of $-2 \mathrm{z}$ scores. ${ }^{16}$ Wasting in particular is assessed with the NCHS/WHO weight for height reference, which compares the child's weight to the average weight of children of the same height. ${ }^{17}$ This ignores the child's age, which allows nutritional status to be assessed when age is not known. It also assumes that, on average, children of a given height weigh the same whatever their age; in infancy and adolescence, however, the weight-height relation depends on age. ${ }^{1819}$

This can be seen by considering the index weight/ height ${ }^{p}$, where the height power $p$ is allowed to vary with age. The index is adjusted for age and sex by dividing it by the same ratio based on median weight and height for the child's age and sex. ${ }^{7}$ For a weight for height index such as NCHS, the value of $p$ is the ratio of the percentage growth rates in weight and height at each age, so it is largest when weight is growing fastest relative to height - that is, in infancy and adolescence when $p$ is 3 or more as against 1.5 in mid-childhood. ${ }^{18}$ In later adolescence, as weight growth continues after height growth has stopped, $p$ increases to infinity and height adjustment becomes impossible. This is an important general limitation of weight for height references in that they cannot be used in adolescence. ${ }^{1820}$ For this reason the NCHS weight for height reference was truncated at age 10 in girls and 11.5 in boys. ${ }^{14}$

The weight/height ${ }^{p}$ index can alternatively be adjusted for height for age, where $p$ is chosen to make the index uncorrelated with height among children at 
each age. This leads to a different pattern of $p$ changing with age, with $p=2$ in infancy, rising to 3 in adolescence and then falling back to 2 in adulthood. ${ }^{192-23}$ Cole suggested fixing $p$ at 2-that is, the body mass index (BMI). ${ }^{21}$ This is now used throughout infancy, childhood, adolescence, and adulthood.

BMI has been used since the 1960 s to assess obesity in adults ${ }^{2425}$ and more recently in children. ${ }^{2627}$ Many countries now have their own national reference centile charts for BMI for age. ${ }^{28-30}$ International BMI cut offs for child overweight and obesity, based on data from six countries, have been developed. ${ }^{31}$

The WHO 1995 expert committee ${ }^{16}$ endorsed the use of BMI for assessing thinness in adolescence, based on the BMI reference data from Must et al, ${ }^{32}$ and the recently published 2006 WHO growth standard also includes BMI for children aged 0-5 years. ${ }^{33}$ However, this is insufficient for international use because the BMI cut offs from Must et al were based on US data from the early 1970s and the WHO standard is restricted in age. Thus there are no valid BMI cut offs for assessing underweight or wasting in adolescents or children over 5 years.

The international BMI cut offs for child overweight and obesity cover the age range 2-18 years and are based on the adult cut offs of 25 and 30 at 18 years. ${ }^{31}$ They have been widely used, with over 1100 citations in the seven years since publication. It would be logical to produce BMI cut offs for underweight using the same principle. However, underweight does not have the same meaning in adults and children. In adults, underweight or thinness indicates low BMI, whereas in children underweight is low weight for age and wasting is low weight for height. ${ }^{16}$ We have extended the adult term of thinness to children, meaning low BMI for age.

\section{METHODS}

\section{Subjects and data}

We used the same methods as those used by the International Obesity TaskForce (IOTF) for the international overweight and obesity cut offs. ${ }^{31} \mathrm{We}$ obtained BMI data from nationally representative surveys of children in six high and middle income countries: Brazil, Great Britain, Hong Kong, the Netherlands, Singapore, and the United States (table 1). ${ }^{31}$ Each survey had over 20000 subjects aged 6-18 years, and height and weight were measured with standard methods and quality control measures to minimise measurement error. Four of the datasets came from one-off surveys, while the British and US data were pooled from surveys collected over a period of time. The US data came from the national health examination surveys II and III, and the national health and nutrition examination surveys (NHANES) I and II, while for comparison Must et al used NHANES I data for their BMI reference. ${ }^{32}$ The Brazilian and US surveys used multi-stage sampling designs, and their data were analysed with survey weights. A total of 192727 subjects were involved, 97876 males and 94851 females from birth to 25 years (table 1).

\section{LMS method}

We analysed each dataset using the LMS method, which summarises the distribution of BMI by age and sex in terms of three curves called L (lambda), M (mu) and $\mathrm{S}$ (sigma)..$^{40}$ The $\mathrm{M}$ curve is median BMI by age, the $\mathrm{S}$ curve is the coefficient of variation of BMI, and the L curve expresses the skewness of the BMI distribution in terms of the Box-Cox power needed to transform the data to near normality. Any required BMI centile curve is defined in terms of the $\mathrm{L}, \mathrm{M}$, and $\mathrm{S}$ curves as follows:

$$
\mathrm{M}(1+\mathrm{L} \times \mathrm{S} \times \mathrm{z})^{1 / \mathrm{L}}
$$

where $\mathrm{z}$ is the $\mathrm{z}$ score corresponding to the required centile (for example, $\mathrm{z}=0$ gives the median $\mathrm{M}$ or $\mathrm{z}=0.67$ gives the 75 th centile) and the values of $\mathrm{L}, \mathrm{M}$, and $S$ vary with age and sex.

The reverse process, of converting a child's BMI to a $\mathrm{z}$ score, involves the equation:

$$
\mathrm{z}=\left((\mathrm{BMI} / \mathrm{M})^{\mathrm{L}}-1\right) /(\mathrm{L} \times \mathrm{S})
$$

where the values of $\mathrm{L}, \mathrm{M}$, and $\mathrm{S}$ are for the child's age and sex. Note that the ratio BMI/M in the second equation, multiplied by 100 , corresponds to BMI expressed as a percentage of the median (BMI $\%$ ). So BMI $\%$ and z are linked in a way that depends on the variability $\mathrm{S}$ and skewness $\mathrm{L}$, which in turn depend on age.

Conventionally a BMI centile chart is based on a prespecified set of centiles (for example, 3rd, 10th, 25th, 50 th, 75 th, 90 th, 97 th $)^{30}$ or $\mathrm{z}$ scores $(-2$ to +2 in increments of two thirds of a z score).$^{41}$ Here by contrast, quasi-centile curves are constructed to pass through a given BMI cut off at a given age (we chose 18 as it was the oldest age with data available in all six datasets). To do this the required BMI is substituted

\begin{tabular}{|c|c|c|c|c|c|c|}
\hline \multirow[b]{2}{*}{ Country } & \multirow[b]{2}{*}{ Year } & \multirow[b]{2}{*}{ Description } & \multicolumn{2}{|c|}{ Boys } & \multicolumn{2}{|c|}{ Girls } \\
\hline & & & Age range & Sample size & Age range & Sample size \\
\hline $\mathrm{Brazil}^{34}$ & 1989 & Second national anthropometric survey & $2-25$ & 15947 & $2-25$ & 15859 \\
\hline Great Britain $^{35}$ & $1978-93$ & Data pooled from five national surveys & $0-23$ & 16491 & $0-23$ & 15731 \\
\hline Hong Kong $^{36}$ & 1993 & National growth survey & $0-18$ & 11797 & $0-18$ & 12168 \\
\hline Netherlands ${ }^{37}$ & 1980 & Third nationwide growth survey & $0-20$ & 21521 & $0-20$ & 20245 \\
\hline Singapore $^{38}$ & 1993 & School health service survey & $6-19$ & 17356 & $6-20$ & 16616 \\
\hline $\mathrm{US}^{39}$ & $1963-80$ & Data pooled from four national surveys & $2-20$ & 14764 & $2-20$ & 14232 \\
\hline Total & 1963-93 & - & $0-25$ & 97876 & $0-25$ & 94851 \\
\hline
\end{tabular}
into the second equation and the corresponding $\mathrm{z}$ 
Table 2 z scores corresponding to different BMI cut offs at age 18, averaged by sex across six datasets

\begin{tabular}{|c|c|c|c|c|c|c|c|c|}
\hline & \multicolumn{2}{|c|}{16} & \multicolumn{2}{|c|}{17} & \multicolumn{2}{|c|}{17.5} & \multicolumn{2}{|c|}{18.5} \\
\hline & Male & Female & Male & Female & Male & Female & Male & Female \\
\hline Mean z score & -2.6 & -2.4 & -1.9 & -1.8 & -1.6 & -1.5 & -1.0 & -1.0 \\
\hline Centile & \multicolumn{2}{|c|}{0.6} & \multicolumn{2}{|c|}{3} & \multicolumn{2}{|c|}{6} & \multicolumn{2}{|c|}{16} \\
\hline
\end{tabular}

score obtained, by using $\mathrm{L}, \mathrm{M}$, and $\mathrm{S}$ values by sex for age 18 specific for the dataset. This $\mathrm{z}$ score is then substituted into the first equation and defines the required curve by age.

We constructed centile curves of this form for each of the six datasets separately and then averaged the curves by age. The result is a single curve, based on all six datasets, that passes through the specified cut off at age 18. This exercise was repeated for each sex and for each of several distinct BMI cut offs at age 18 .

\section{Choice of cut offs at age 18}

The international cut offs for overweight and obesity were based on the widely accepted adult BMI values of 25 and $30 .{ }^{31}$ These values are related to health, indicating points on the BMI spectrum where risk increases appreciably, and are widely used. ${ }^{25}$ Health related cut offs for thinness in adults also exist, but there is less consensus in their use. WHO defines thinness grades 1,2 , and 3 as BMI below $18.5,17$, and $16^{1642}$; the malnutrition universal screening tool of the British Association for Parental and Enteral Nutrition (BAPEN) scores 1 and 2 for BMI below 20 and 18.5, respectively ${ }^{43}$; and the WHO ICD-10 criteria for anorexia nervosa include BMI below 17.5 or weight below $85 \%$ of expected weight for height. ${ }^{445}$

In children, the diagnostic criteria for anorexia nervosa use BMI below the 5th or 10th centile, corresponding to -1.6 or $-1.3 \mathrm{SD}$ ( $\mathrm{z}$ scores), to define underweight, ${ }^{4647}$ while the criteria for malnutrition, based on weight for height rather than BMI, use the graded WHO cut offs of $-1,-2$, and $-3 \mathrm{SD}$, corresponding roughly to $90 \%, 80 \%$, and $70 \%$ of expected weight for height. ${ }^{1648}$ Anomalously the WHO Expert Committee ${ }^{16}$ defined thinness in adolescence as BMI below the 5 th centile rather than below $-2 \mathrm{SD}$, probably because the NHANES I reference did not provide -2 SD cut offs. At age 18 the 5 th centiles in Must et al were 17.5 for males and 16.7 for females, reflecting US youth in the early $1970 \mathrm{~s}^{32}$

Table $3 \mid z$ scores corresponding to BMI 17 at age 18 by sex across datasets

\begin{tabular}{lcccccc} 
& \multicolumn{3}{c}{ Males } & & \multicolumn{2}{c}{ Females } \\
\cline { 2 - 3 } \cline { 6 - 7 } Country & Centile & z score & & Centile & z score \\
Brazil & 3 & -1.9 & & 2 & -2.0 \\
\hline Great Britain & 2 & -2.2 & & 2 & -2.0 \\
\hline Hong Kong & 9 & -1.3 & & 6 & -1.6 \\
\hline Netherlands & 2 & -2.2 & & 3 & -1.9 \\
\hline Singapore & 6 & -1.5 & & 9 & -1.3 \\
\hline US & 1 & -2.4 & & 3 & -2.0 \\
\hline
\end{tabular}

An important question here is which cut off is the more appropriate, the 5 th centile or $-2 \mathrm{SD}$. WHO recommended the $-2 \mathrm{SD}$ criterion back in $1977,{ }^{13}$ while the 5 th centile was a pragmatic alternative at a time when a -2 SD BMI cut off was not available. For this reason we feel that $-2 \mathrm{SD}$ is the more appropriate cut off to use.

On this basis, the simplest way to transfer the child cut offs from weight for height to BMI is to treat the two -2 SD cut offs as equivalent. Weight for height is weight adjusted for height while BMI for age is weight adjusted for height and age. So if weight for height were independent of age, as it is at certain ages, ${ }^{18}$ then the two cut offs would coincide. At other ages the variability in BMI is theoretically slightly less than for weight for height, as variability caused by age is adjusted for. Against that, the height adjustment for BMI is imperfect later in childhood, ${ }^{19}$ so on balance the variability is likely to be similar for the two indices.

Thus the optimal cut off for our purposes would be a value of BMI at age 18 that coincided with a previously published adult cut off and which was also close to a child BMI cut off of -2 SD. But this introduces ambiguity as the $\mathrm{z}$ score corresponding to a given cut off will depend on the growth reference used. Here we use the six datasets as internal references to test the alternative cut offs. We also investigate the relation between $\mathrm{z}$ score and $\mathrm{BMI} \%$.

\section{RESULTS}

Table 2 gives BMI z scores and centiles corresponding to various published BMI cut offs at age 18, averaged across the six datasets, where the centiles correspond to the sex averaged $\mathrm{z}$ scores. In general the results are similar for boys and girls, and the cut offs range from the 0.6 th to the 16 th centile. BMI 18.5 is on the 16 th centile and approximates to a $\mathrm{z}$ score of -1 , while BMI 17 is on the 3rd centile and close to $\mathrm{z}$ score -2 , and hence is near optimal for our purposes.

Table 3 looks at the BMI cut off of 17 in z score terms by dataset. The four Western countries are close to $\mathrm{z}$ score -2.0 in females and -2.1 in males, while the data from Hong Kong and Singapore are near to -1.4 . The centiles indicate the prevalence of thinness in each country at age 18 when the survey was done, at which time the East Asian children were appreciably thinner.

Figure 1 shows the separate thinness curves for BMI 17 at age 18 by country and sex. Within each graph the country curves are largely superimposed and more so for girls than boys. Looking at the individual countries, Brazil is relatively low in both sexes while Hong Kong is high in boys, and for Singapore the boys' curve stands out at age 6 .

The BMI cut off of 17 is not only near to $\mathrm{z}$ score -2 , it is also the WHO definition of thinness grade 2 in adults. Thus the WHO classification provides a bridge between child and adult, in that a young person with BMI 17 at age 18 is both a borderline thin adult (grade 2 ) and a borderline thin child (z score -2$)$. For this reason we propose to use the cut off of 17 plus the other 

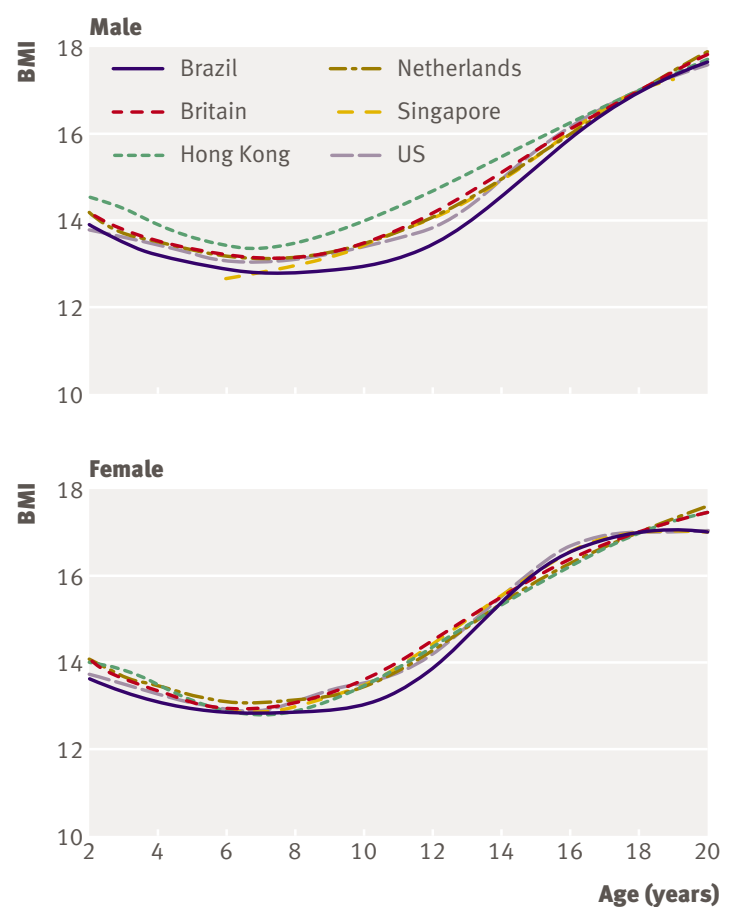

Fig 1 Centiles by age and sex defined to pass through BMI 17 at age 18 years in six datasets

two WHO cut offs of 18.5 and 16 as the basis for our classification.

Figure 2 shows the thinness curves by country for BMI 18.5 at age 18, where the agreement between datasets is closer than for figure 1. Singapore is again anomalous at age 6 , notably in the boys, probably because of the absence of data below this age.

Figure 3 shows the same curves for a cut off of BMI 16 , where the agreement between countries is noticeably poorer, particularly in the boys, reflecting the greater extrapolation into the tails of the BMI distributions.

Figure 4 shows the composite curves for cut offs 16 , 17 , and 18.5 , obtained by averaging the individual curves in figures 1,2 , and 3 . To avoid a discontinuity at age 6 we smoothed the mean values with and without Singapore between ages 6 and 8 . Table 4 gives the values of the curves by exact half year from 2 to 18 years, and values for intermediate ages can be obtained by interpolation.

Table 5 shows the relation between BMI $\%$ and BMI $z$ score at different ages, averaged across the datasets by sex, where the centiles correspond to the sex averaged $\mathrm{z}$ scores. Up to 6 years a $\mathrm{z}$ score of -2 corresponds to BMI $85 \%$ of the median, while from 14 years the same $\mathrm{z}$ score matches BMI $80 \%$. This shift with age is caused largely by the sharp increase in variability in BMI that occurs between 6 and 12 years. The plot of the coefficient of variation of BMI (the $S$ curve) against age by country ${ }^{31}$ shows it clearly, where all six countries follow the same pattern of an early plateau then a rise, then a later plateau.
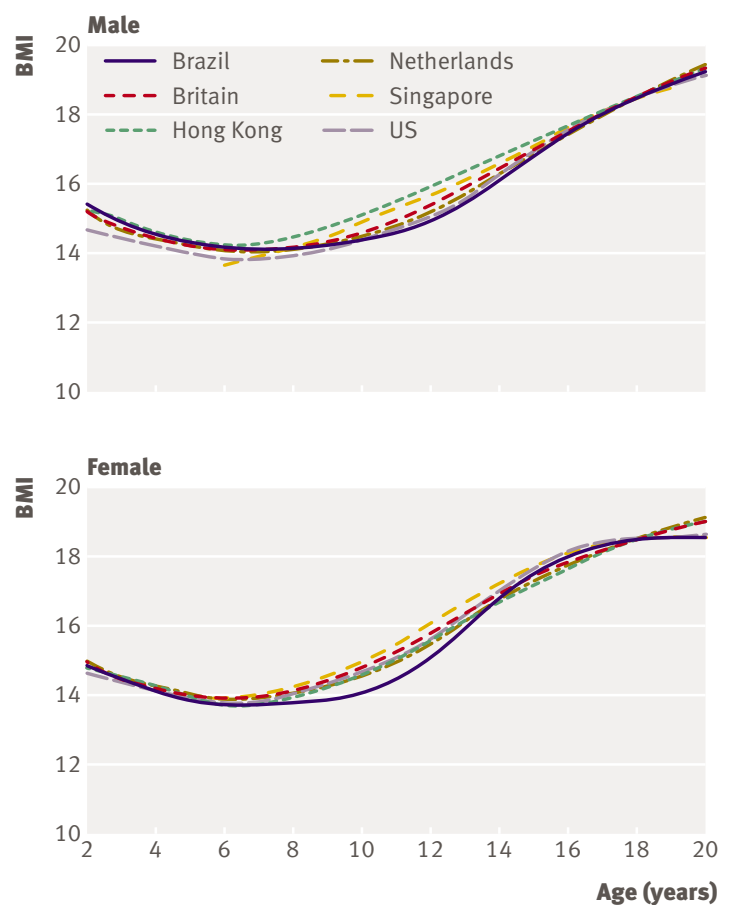

Fig 2 Centiles by age and sex defined to pass through BMI 18.5 at age 18 years in six datasets
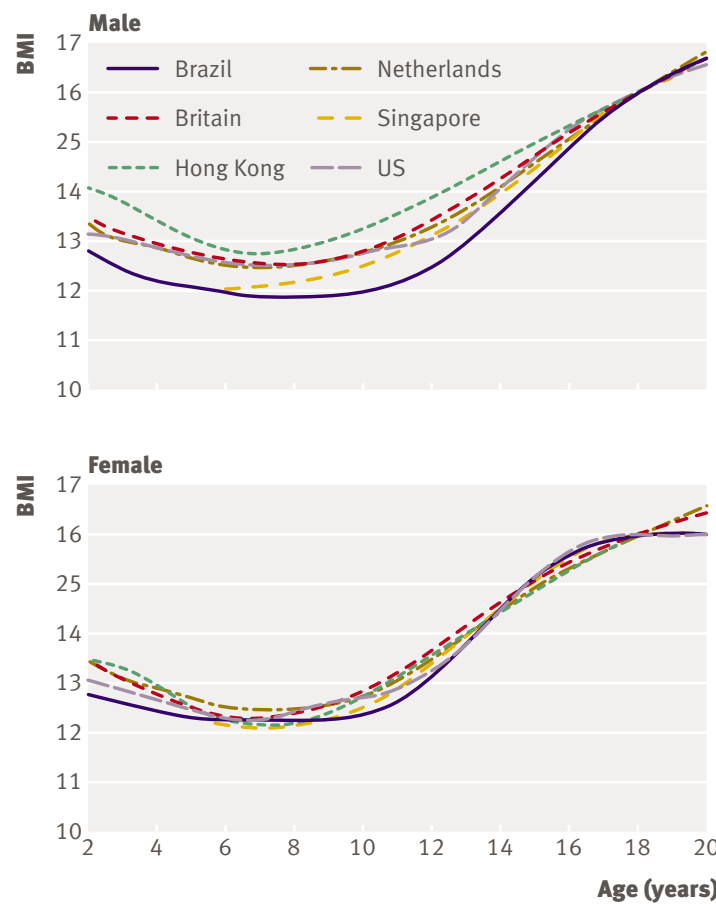

Fig $3 \mid$ Centiles by age and sex defined to pass through BMI 16 at age 18 years in six datasets

\section{DISCUSSION}

We propose that a BMI of 17 at age 18 is a suitable cut off to use as the basis for an international definition of thinness in children and adolescents. Three different criteria lead to this conclusion: BMI 17 is the WHO 
grade 2 cut off for thinness in adults ${ }^{16} ;$ BMI 17 at age 18 corresponds to a mean $\mathrm{z}$ score of -2 using our data (table 2); and, again with our data, BMI 17 at age 18 is $80 \%$ of the median (table 5). The latter two criteria mean that in childhood the new cut off will be similar in $\mathrm{z}$ score and $\%$ of the median terms to those used before, notably the WHO definition of wasting - that is, weight for height below $-2 \mathrm{SD}$ or $80 \%$ of the median.

WHO defines thinness in adolescents ${ }^{16}$ as BMI below the smoothed 5 th centile for age from Must et al cut offs that at age 18 are 17.5 for males and 16.7 for females. ${ }^{32}$ For comparison a cut off of 17 applied to our US data in table 3 (four surveys including NHANES I) corresponds to the 1 st centile in boys and 2 nd centile in girls. Using a cut off nearer the 2 nd than the 5 th centile seems reasonable in that $\mathrm{WHO}$, which has always used a -2 SD cut off, opted for the 5th BMI centile of the Must et al reference only because there was no alternative. Using 17 as the cut off would unify the two WHO

Table 4 | International cut-off points for BMI for thinness grades 1, 2, and 3 by sex for exact ages between 2 and 18 years, defined to pass through BMI of 16,17 , and 18.5 at age 18 , obtained by averaging data from Brazil, Great Britain, Hong Kong, Netherlands, Singapore, and US

\begin{tabular}{|c|c|c|c|c|c|c|}
\hline \multirow[b]{2}{*}{ Age (years) } & \multicolumn{3}{|c|}{ Boys } & \multicolumn{3}{|c|}{ Girls } \\
\hline & 16 & 17 & 18.5 & 16 & 17 & 18.5 \\
\hline 2.0 & 13.37 & 14.12 & 15.14 & 13.24 & 13.90 & 14.83 \\
\hline 2.5 & 13.22 & 13.94 & 14.92 & 13.10 & 13.74 & 14.63 \\
\hline 3.0 & 13.09 & 13.79 & 14.74 & 12.98 & 13.60 & 14.47 \\
\hline 3.5 & 12.97 & 13.64 & 14.57 & 12.86 & 13.47 & 14.32 \\
\hline 4.0 & 12.86 & 13.52 & 14.43 & 12.73 & 13.34 & 14.19 \\
\hline 4.5 & 12.76 & 13.41 & 14.31 & 12.61 & 13.21 & 14.06 \\
\hline 5.0 & 12.66 & 13.31 & 14.21 & 12.50 & 13.09 & 13.94 \\
\hline 5.5 & 12.58 & 13.22 & 14.13 & 12.40 & 12.99 & 13.86 \\
\hline 6.0 & 12.50 & 13.15 & 14.07 & 12.32 & 12.93 & 13.82 \\
\hline 6.5 & 12.45 & 13.10 & 14.04 & 12.28 & 12.90 & 13.82 \\
\hline 7.0 & 12.42 & 13.08 & 14.04 & 12.26 & 12.91 & 13.86 \\
\hline 7.5 & 12.41 & 13.09 & 14.08 & 12.27 & 12.95 & 13.93 \\
\hline 8.0 & 12.42 & 13.11 & 14.15 & 12.31 & 13.00 & 14.02 \\
\hline 8.5 & 12.45 & 13.17 & 14.24 & 12.37 & 13.08 & 14.14 \\
\hline 9.0 & 12.50 & 13.24 & 14.35 & 12.44 & 13.18 & 14.28 \\
\hline 9.5 & 12.57 & 13.34 & 14.49 & 12.53 & 13.29 & 14.43 \\
\hline 10.0 & 12.66 & 13.45 & 14.64 & 12.64 & 13.43 & 14.61 \\
\hline 10.5 & 12.77 & 13.58 & 14.80 & 12.78 & 13.59 & 14.81 \\
\hline 11.0 & 12.89 & 13.72 & 14.97 & 12.95 & 13.79 & 15.05 \\
\hline 11.5 & 13.03 & 13.87 & 15.16 & 13.15 & 14.01 & 15.32 \\
\hline 12.0 & 13.18 & 14.05 & 15.35 & 13.39 & 14.28 & 15.62 \\
\hline 12.5 & 13.37 & 14.25 & 15.58 & 13.65 & 14.56 & 15.93 \\
\hline 13.0 & 13.59 & 14.48 & 15.84 & 13.92 & 14.85 & 16.26 \\
\hline 13.5 & 13.83 & 14.74 & 16.12 & 14.20 & 15.14 & 16.57 \\
\hline 14.0 & 14.09 & 15.01 & 16.41 & 14.48 & 15.43 & 16.88 \\
\hline 14.5 & 14.35 & 15.28 & 16.69 & 14.75 & 15.72 & 17.18 \\
\hline 15.0 & 14.60 & 15.55 & 16.98 & 15.01 & 15.98 & 17.45 \\
\hline 15.5 & 14.86 & 15.82 & 17.26 & 15.25 & 16.22 & 17.69 \\
\hline 16.0 & 15.12 & 16.08 & 17.54 & 15.46 & 16.44 & 17.91 \\
\hline 16.5 & 15.36 & 16.34 & 17.80 & 15.63 & 16.62 & 18.09 \\
\hline 17.0 & 15.60 & 16.58 & 18.05 & 15.78 & 16.77 & 18.25 \\
\hline 17.5 & 15.81 & 16.80 & 18.28 & 15.90 & 16.89 & 18.38 \\
\hline 18.0 & 16.00 & 17.00 & 18.50 & 16.00 & 17.00 & 18.50 \\
\hline
\end{tabular}

definitions of thinness, for adults and adolescents, while extending its use to children too.

We have tried to avoid potential confusion between the terms "wasting" and "underweight" in children by adopting the term "thinness," which WHO uses to mean low BMI in adults and adolescents. We extend the definition to include low BMI for age in children, linked to the adult definition through the fulcrum of BMI 17 at age 18. It is important to recognise, however, that thinness is not simply the opposite of fatness-a low BMI is more strongly correlated with lean mass than fat mass. ${ }^{49}$

Pelletier and Frongillo emphasise that most mortality related to malnutrition occurs with mild or moderate malnutrition ${ }^{3}$ so there is a need to distinguish between grades of malnutrition. In addition to our primary cut off of 17 we propose two secondary cut offs: 18.5 , long used by WHO in adult studies ${ }^{42}$ and for grade 1 thinness, ${ }^{16}$ and 16 , used for grade 3 thinness. Thus our three cut offs correspond to the WHO graded definition of thinness.

Surprisingly, given its key role in the assessment of malnutrition, weight for height is poorer than weight for age or mid-arm circumference for predicting mortality. ${ }^{2}$ Pelletier's review summarises eight studies that compare anthropometric indicators for predicting mortality and shows that weight for height is consistently the least effective. ${ }^{2}$ Pelletier suggests that increased measurement error may explain this, but other possibilities are the use of weight for height rather
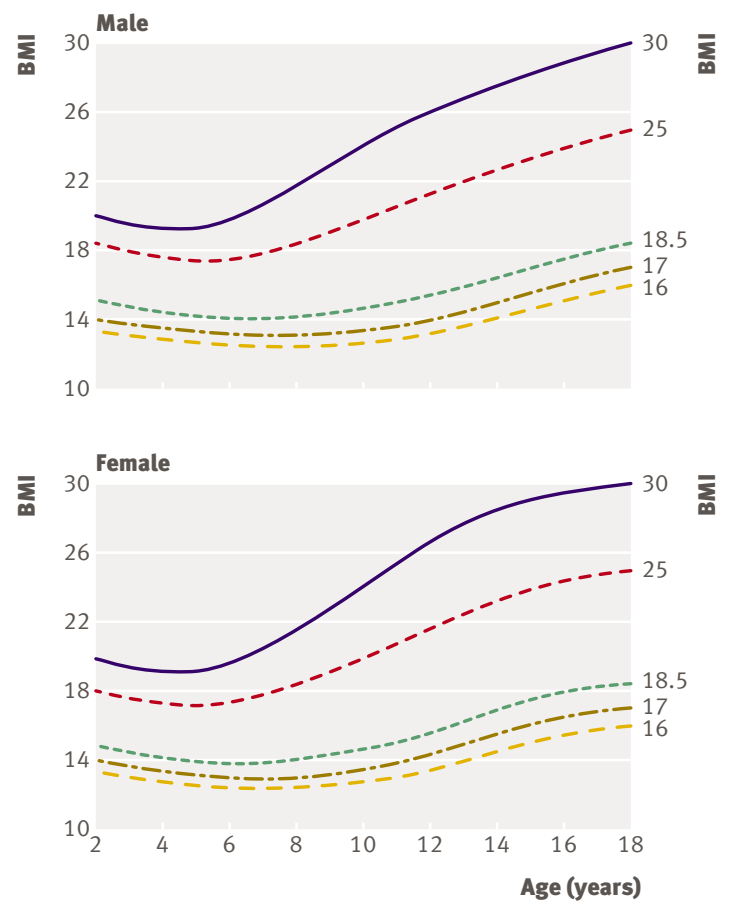

Fig $4 \mid$ Cut offs for thinness by age and sex defined to pass through BMI 16, 17, and 18.5 at 18 years, with the international cut offs for overweight and obesity based on BMI 25 and $30^{31}$ 
Table $5 \mid \mathrm{z}$ scores and centiles corresponding to $\mathrm{BMI}$ as $\%$ of median, by age from 2-18 years, averaged by sex across six datasets

\begin{tabular}{|c|c|c|c|c|c|c|}
\hline \multirow[b]{2}{*}{ Age } & \multicolumn{2}{|c|}{$75 \% \mathrm{BMI}$} & \multicolumn{2}{|c|}{$80 \% \mathrm{BMI}$} & \multicolumn{2}{|c|}{$85 \%$ BMI } \\
\hline & Male & Female & Male & Female & Male & Female \\
\hline \multicolumn{7}{|l|}{2 years } \\
\hline z score & -4.1 & -3.9 & -3.1 & -2.9 & -2.2 & -2.1 \\
\hline Centile & \multicolumn{2}{|c|}{0.003} & \multicolumn{2}{|c|}{0.1} & \multicolumn{2}{|c|}{2} \\
\hline \multicolumn{7}{|l|}{6 years } \\
\hline z score & -4.0 & -3.6 & -2.9 & -2.7 & -2.0 & -1.9 \\
\hline Centile & \multicolumn{2}{|c|}{0.007} & \multicolumn{2}{|c|}{0.3} & \multicolumn{2}{|c|}{3} \\
\hline \multicolumn{7}{|c|}{10 years } \\
\hline z score & -3.3 & -2.9 & -2.4 & -2.1 & -1.6 & -1.5 \\
\hline Centile & \multicolumn{2}{|c|}{0.1} & \multicolumn{2}{|c|}{1} & \multicolumn{2}{|c|}{6} \\
\hline \multicolumn{7}{|c|}{14 years } \\
\hline z score & -2.9 & -2.6 & -2.2 & -1.9 & -1.5 & -1.4 \\
\hline Centile & \multicolumn{2}{|c|}{0.3} & \multicolumn{2}{|c|}{2} & \multicolumn{2}{|c|}{8} \\
\hline \multicolumn{7}{|c|}{18 years } \\
\hline z score & -2.9 & -2.7 & -2.1 & -2.0 & -1.5 & -1.4 \\
\hline Centile & \multicolumn{2}{|c|}{0.2} & \multicolumn{2}{|c|}{2} & \multicolumn{2}{|c|}{7} \\
\hline
\end{tabular}

than BMI and unsuitable cut offs. The three BMI cut offs proposed here allow this to be tested.

The recent publication of the WHO child growth standard ${ }^{33}$ is likely in time to have a major impact on the growth assessment of young children. The centiles on the WHO BMI chart overlap with our proposed cut offs between 2 and 5 years, and figure 5 shows how the two compare (including the BMI 25 and 30 cut offs $^{31}$ ). The BMI 17 cut off lies between the WHO -1 and -2 SD curves and corresponds to the 5-7th WHO centile, somewhat higher than the 3rd centile seen in table 2 . This reflects the fact that the $-2 \mathrm{SD}$ curve is lower in the WHO standard than in our data (table 1) and other references such as the CDC 2000 reference. ${ }^{5051}$ Thus far there is no advice from WHO about how to use the $\mathrm{BMI}$ chart for assessment of malnutrition.

\section{Limitations and strengths}

The key assumption of our analysis is that the cut offs have the same meaning irrespective of age, sex, and country. This is inevitably a simplification of a complex situation. The choice of 18 as the crossover age between child and adult is not ideal as BMI increases after this age faster in males than females. Age 20 would have been better, but some of our datasets lacked data at that age. In the datasets extending to age 20, BMI 17 at age 18 corresponded to BMI 17.7 in males and 17.2 in females at age 20 (fig 1), a slight male excess. ${ }^{52}$ Adjustment for this would make the cut offs for the two sexes closer together at young ages but further apart after age 10. Overall the male cut offs are slightly more extreme (table 2). Also the two East Asian countries (Hong Kong and Singapore) have appreciably higher prevalences of thinness than the other countries (table 3), which arise from their greater variability in BMI. ${ }^{31}$

The lack of an adjustment for puberty is another limitation of the cut offs. BMI is known to be higher in more mature individuals of the same age, ${ }^{853}$ and delayed puberty is associated with thinness ${ }^{54}$ which an adjustment for pubertal stage might avoid. Such an adjustment is statistically complex but should be considered in the application of the cut offs to populations with delayed puberty, just as with linear growth.

Finally, BMI is based on weight and does not differentiate between fat mass and lean mass, therefore it is an imperfect measure of either adiposity or leanness. In children it correlates with fat mass more strongly at the upper end of the adiposity spectrum (where fat mass makes up a larger proportion of weight) than at the lower end. ${ }^{49}$ So in thin children BMI is a better predictor of lean mass than fat mass.

We believe that none of these differences invalidates the underlying principle of the cut offs, which is to provide a simple yet "good enough" tool to compare prevalences across populations that are inevitably heterogeneous. As with any screening tool its sensitivity and specificity need testing in the field.

The main strength of the cut offs is their ability to compare rates of prevalence of thinness across countries, regions, and time. The cut offs avoid the conventional concept of a reference population in that they include data from several disparate populations, so they are at the same time representative of several countries and of none. This duality increases the perceived generalisability of the cut offs, even though they clearly cannot be universally representative. Instead a
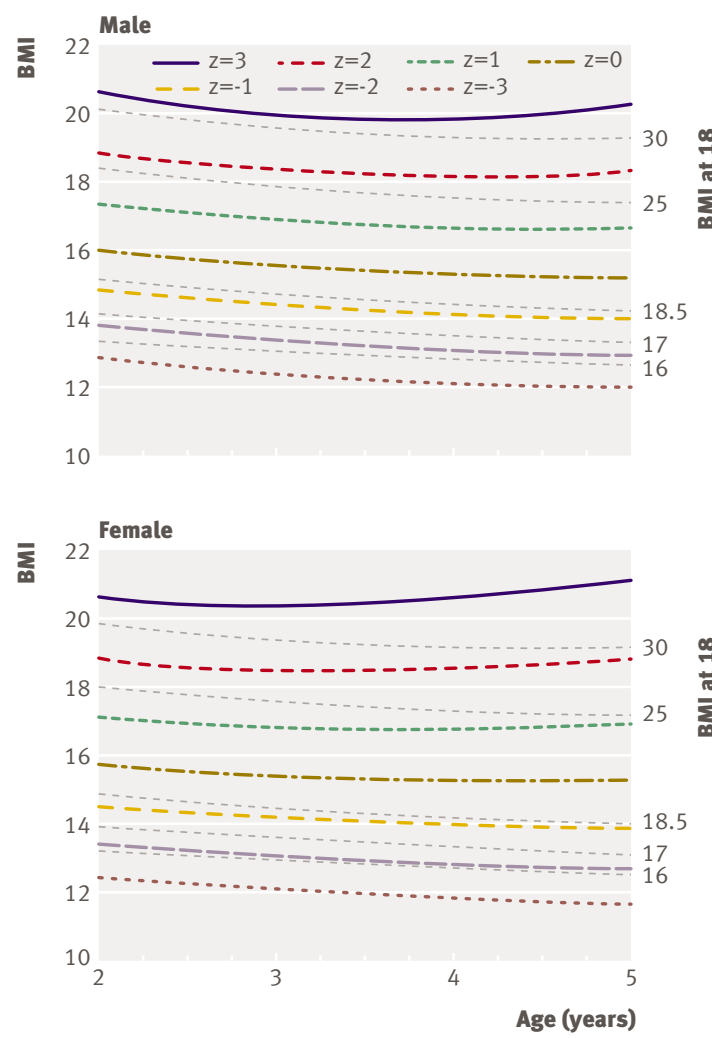

Fig 5 | Comparison of cut offs for BMI at 18 and WHO BMI growth standard $z$ scores from -3 to $3^{33}$ at ages 2-5 years 


\section{WHAT IS ALREADY KNOWN ON THIS TOPIC}

Malnutrition in children and adolescents is a serious public health concern

It is better assessed as thinness (low body mass index for age) than as wasting (low weight for height)

There are no suitable thinness cut offs for this age group

\section{WHAT THIS STUDY ADDS}

A new graded definition of thinness in childhood and adolescence is proposed, based on pooled international data for $\mathrm{BMI}$ and linked to the WHO recommended adult cut off points of 16,17 , and 18.5 at age 18

The thinness cut off linked to 17 is close to the wasting cut off based on $-2 \mathrm{z}$ scores

The new definitions should encourage direct comparison of trends in child and adolescent thinness worldwide
Finally, we emphasise that these cut offs need to be tested against new data; they are offered as a way forward and not as a definitive statement. But we hope they will prove helpful in providing a unified definition of thinness in children and adolescents based on thinness in adults. They can also be used in conjunction with the corresponding international definition of overweight and obesity.

We thank Carlos Monteiro (Brazil), Sophie Leung (Hong Kong), Machteld Roede (Netherlands), and Uma Rajan (Singapore) for allowing us access to their data.

Contributors: TJC and DN had the original idea. TJC did most of the statistical analyses, wrote the first draft, and is guarantor. KMF did further analyses of the US data. DN provided expertise on eating disorders and AAI provided expertise on malnutrition. All authors participated in the discussion and interpretation of the results and contributed to the final paper.

fixed BMI in adulthood acts as the reference point. A side effect of this is that because there is no reference, there are also no underlying $\mathrm{z}$ scores-individuals can be classified only relative to the cut offs in figure 4 and table 4. Also, the cut offs are resilient to the possible addition of other datasets to the reference because of the way they are constructed. Adding, for example, an African dataset would have no effect on the cut offs at age 18 because of the standardisation to that age and only a modest effect at other ages because of dilution with the existing datasets, depending of course on the shape of the new BMI centile curve compared with the existing cut offs.

The cut offs provide a classification of thinness for public health purposes, while BMI centiles have a valuable role to play in the clinical management of individuals, where the changes in BMI over time can be judged relative to the BMI centile chart. They are two different but complementary ways of assessing BMI.

\section{Implications for practice and policy}

We have previously described the international cut offs for overweight and obesity ${ }^{31}$ and discussed several issues about their use and interpretation that are just as relevant for cut offs for thinness. One issue not discussed there is the best way to report prevalence rates. The category of overweight, for example, can be defined either as the proportion of children with BMI beyond the overweight cut off or the proportion with BMI between the overweight and obesity cut offs. So the overweight group either does or does not include the obese group, and quite often papers fail to indicate which definition was used, beyond or between. Our preference is between, so that, for example, grade 1 thinness implies a BMI between the 17 and $<18.5$ cut offs. To this end we have developed a Microsoft Excel add-in module called lmsGrowth, ${ }^{55}$ which (inter alia) converts BMI to an ordered grade by interpolating to the child's exact age. The module codes normal weight (between the 18.5 and $<25$ cut offs) as 0 and overweight $(25$ to $<30)$ and obesity $(\geq 30)$ as +1 and +2 , respectively, while thinness grades 1,2 , and 3 are coded as $-1(17$ to $<18.5),-2(16$ to $<17)$, and -3 $(<16)$.
Funding: Research at the UCL Institute of Child Health and Great Ormond Street Hospital for Children NHS Trust benefits from funding from the N HS Executive. TJC is supported by a Medical Research Council programme grant.

Competing interests: None declared.

Ethical approval: Not required.

1 Lobstein T, Baur L, Uauy R. Obesity in children and young people: a crisis in public health. Obes Rev 2004;5(suppl 1):4-85.

2 Pelletier DL. The relationship between child anthropometry and mortality in developing countries: implications for policy, programs and future research. I Nutr 1994;124:2047-81S.

3 Pelletier DL, Frongillo EA. Changes in child survival are strongly associated with changes in malnutrition in developing countries. J Nutr 2003;133:107-19.

4 El-Ghannam AR. The global problems of child malnutrition and mortality in different world regions. J Health Soc Policy 2003;16:1-26.

5 Staton DM, Harding MH. Protecting child health worldwide. Implementation is the biggest challenge slowing efforts to reduce childhood morbidity and mortality in developing countries. Pediatr Ann 2004;33:647-55.

6 Lucas AR, Beard CM, O'Fallon WM, Kurland LT. 50-year trends in the incidence of anorexia nervosa in Rochester, Minn.: a populationbased study. Am / Psychiatry 1991;148:917-22.

7 Cole TJ. Weight-stature indices to measure underweight, overweight and obesity. In: Himes JH, ed. Anthropometric assessment of nutritional status. New York: Wiley-Liss, 1991:83-111.

8 Woodruff BA, Duffield A. Anthropometric assessment of nutritional status in adolescent populations in humanitarian emergencies. Eur J Clin Nutr 2002;56:1108-18.

9 Gomez F, Ramos-Galvan R, Frenk S, Cravioto JM, Chavez R, Vasquez J. Mortality in second and third degree malnutrition. J Trop Pediatr 1956;2:77.

10 De Onis M. Measuring nutritional status in relation to mortality. Bull World Health Organ 2000;78:1271-4.

11 Seoane N, Latham MC. Nutritional anthropometry in the identification of malnutrition in childhood. J Trop Pediatr Environ Child Health 1971;17:98-104.

12 Waterlow JC. Classification and definition of protein-calorie malnutrition. BMJ 1972;3:566-9.

13 Waterlow JC, Buzina R, Keller W, Lane JM, Nichaman MZ, Tanner JM. The presentation and use of height and weight data for comparing the nutritional status of groups of children under the age of 10 years. Bull World Health Organ 1977;55:489-98.

14 Hamill PVV, Drizd TA, Johnson CL, Reed RB, Roche AF. NCHS growth curves for children birth-18 years. Washington DC: National Center for Health Statistics, 1977.

15 Lavoi-Pierre GJ, Keller W, Dixon H, Dustin JP, TenDam G. Measuring change in nutritional status. Guidelines for assessing the nutritional impact of supplementary feeding programmes for vulnerable groups. Geneva: WHO, 1983.

16 WHO. Physical status: the use and interpretation of anthropometry. Geneva: WHO, 1995.

17 Jelliffe DB. The assessment of nutritional status of the community. Geneva: WHO, 1966.

18 Cole TJ. A critique of the NCHS weight for height standard. Hum Bio 1985;57:183-96.

19 Cole TJ. Weight/height ${ }^{p}$ compared to weight/height ${ }^{2}$ for assessing adiposity in childhood: influence of age and bone age on p during puberty. Ann Hum Biol 1986;13:433-51.

20 Flegal KM, Wei R, Ogden C. Weight-for-stature compared with body mass index-for-age growth charts for the United States from the 
Centers for Disease Control and Prevention. Am J Clin Nutr 2002;75:761-6.

21 Cole TJ. A method for assessing age-standardized weight-for-height in children seen cross-sectionally. Ann Hum Biol 1979;6:249-68.

22 Hattori K, Hirohara T. Age change of power in weight/height(p) indices used as indicators of adiposity in Japanese. Am J Hum Biol 2002;14:275-9.

23 Rolland-Cachera MF, Sempé M, Guilloud-Bataille M, Patois E, Pequignot-Guggenbuhl F, Fautrad V. Adiposity indices in children. Am J Clin Nutr 1982;36:178-84.

24 Keys A, Fidanza F, Karvonen MJ, Kimura N, Taylor HL. Indices of relative weight and obesity. J Chron Dis 1972;25:329-43.

25 Garrow JS, Webster J. Quetelet's index $\left(\mathrm{W} / \mathrm{H}^{2}\right)$ as a measure of fatness. Int J Obesity 1985;9:147-53.

26 Dietz WH, Robinson TN. Use of the body mass index (BMI) as a measure of overweight in children and adolescents. J Pediatr 1998;132:191-3.

27 Poskitt EME. Body mass index and child obesity: are we nearing a definition? Acta Paediatr 2000;89:507-9.

28 Cole TJ, Freeman JV, Preece MA. Body mass index reference curves for the UK, 1990. Arch Dis Child 1995;73:25-9.

29 Fredriks AM, van Buuren S, Wit JM, Verloove Vanhorick SP. Body mass index measurements in 1996-7 compared with 1980. Arch Dis Child 2000;82:107-12.

30 Ogden CL, Kuczmarski RJ, Flegal KM, Mei Z, Guo S, Wei R, et al. Centers for Disease Control and Prevention 2000 growth charts for the United States: improvements to the 1977 National Center for Health Statistics version. Pediatrics 2002;109:45-60.

31 Cole TJ, Bellizzi MC, Flegal KM, Dietz WH. Establishing a standard definition for child overweight and obesity: international survey. $B M$ 2000;320:1240-3.

32 Must A, Dallal GE, Dietz WH. Reference data for obesity: 85th and 95th percentiles of body mass index $\left(\mathrm{wt} / \mathrm{ht}^{2}\right)$ and triceps skinfold thickness. Am J Clin Nutr 1991;53:839-46.

33 WHO Multicentre Growth Reference Study Group. WHO child growth standards based on length/height, weight and age. Acta Paediatr 2006;(suppl 450):76-85.

34 Monteiro CA, Benicio MHDA, lunes RF, Gouveia NC, Taddei JAAC, Cardoso MAP. Nutritional status of Brazilian children: trends from 1975 to 1989. Bull World Health Organ 1992;70:657-66.

35 Cole TJ, Freeman JV, Preece MA. British 1990 growth reference centiles for weight, height, body mass index and head circumference fitted by maximum penalized likelihood. Stat Med 1998;17:407-29.

36 Leung SSF, Cole TJ, Tse LY, Lau JTF. Body mass index reference curves for Chinese children. Ann Hum Biol 1998;25:169-74.

37 Cole TJ, Roede MJ. Centiles of body mass index for Dutch children aged 0-20 years in 1980-a baseline to assess recent trends in obesity. Ann Hum Biol 1999;26:303-8.

38 Rajan U. Obesity among Singapore students. Int J Obesity 1994;18(suppl 2):27.
39 Troiano RP, Flegal KM. Overweight children and adolescents: description, epidemiology, and demographics. Pediatrics 1998;101:497-504.

40 Cole TJ, Green PJ. Smoothing reference centile curves: the LMS method and penalized likelihood. Stat Med 1992;11:1305-19.

41 Cole TJ. Do growth chart centiles need a face lift? BMJ 1994;308:641-2.

42 James WPT, Ferroluzzi A, Waterlow JC. Definition of chronic energy deficiency in adults-report of a working party of the international dietary energy consultative group. Eur J Clin Nutr 1988;42:969-81.

43 Stratton RJ, Hackston A, Longmore D, Dixon R, Price S, Stroud M, et al. Malnutrition in hospital outpatients and inpatients: prevalence, concurrent validity and ease of use of the "malnutrition universal screening tool" ("MUST") for adults. Br J Nutr 2004;92:799-808.

44 American Psychiatric Association. Diagnostic and statistical manual of mental disorders. 4th ed. Washington DC: APA, 2000.

45 World Health Organization. The ICD-10 classification of mental and behavioural disorders. Geneva: WHO, 1993.

46 Hebebrand J, Himmelmann GW, Heseker H, Schafer $\mathrm{H}$, Remschmidt $\mathrm{H}$. Use of percentiles for the body mass index in anorexia nervosa: diagnostic, epidemiological, and therapeutic considerations. Int J Eat Disord 1996;19:359-69.

47 Selzer R, Bowes G, Patton G. When is an adolescent too thin? Am J Psychiatry 1995;152:813-4.

48 Golden MHN, Golden BE. Severe malnutrition. In: Garrow JS, James WPT, Ralph A, eds. Human nutrition and dietetics. 10th ed. Edinburgh: Churchill Livingstone, 2000:517-26.

49 Freedman DS, Wang J, Maynard LM, Thornton JC, Mei Z, Pierson RN, et al. Relation of BMI to fat and fat-free mass among children and adolescents. Int J Obes 2005;29:1-8.

50 Onyango AW, de Onis M, Caroli M, Shah U, Sguassero Y, Redondo N, et al. Field-testing the WHO child growth standards in four countries. Nutr 2007;137:149-52.

51 Seal A, Kerac M. Operational implications of using 2006 World Health Organization growth standards in nutrition programmes: secondary data analysis. BMJ 2007;334:733.

52 Chinn S, Rona RJ. International definitions of overweight and obesity for children: a lasting solution? Ann Hum Biol 2002;29:306-13.

53 Sandhu J, Ben-Shlomo Y, Cole TJ, Holly J, Davey Smith G. The impact of childhood body mass index on timing of puberty, adult stature and obesity: a follow-up study based on adolescent anthropometry recorded at Christ's Hospital (1936-1964). Int J Obes 2006;30:14-22.

54 Nicholls D. Reading the signs of starvation. Acta Paediatr 2005;94:1356-8.

55 Pan H, Cole TJ. ImsGrowth, a Microsoft Excel add-in to access growth references based on the LMS method. Version 2.2. 2007. www. healthforallchildren.co.uk/.

Accepted: 18 May 2007 